\title{
Study on the Ancient Art Fire Sickle of China
}

\author{
Lijuan Dai \\ Xiamen Arts and Design Collge \\ Fuzhou University \\ Xiamen, Fujian, China
}

\begin{abstract}
In ancient time, people used to take iron to knock fire sickle into fires which has lasted for thousands of years. As time flies, the tradition of fire sickle and tools are gradually disappear in our life. This paper attempts to characterize the structure of the fire sickle, modeling implication and the evolution of function and so on to elaborate the artistic value of fire sickle. The formation of the fire sickle has fully demonstrated the ancient craftsmen exquisite handmade skills with rich imagination and creativity. This will provide great reference value for the modern gas appliance.
\end{abstract}

\section{Keywords-Firearms; Fire Sickle; Artistic value}

\section{INTRODUCTION}

"Sui people was the one who began to drill wood for fire,different from the animal,they used fire to cook their food for people so that they would not get any abdominal disease"; " They used wood to get fire, and they used the fire to cook their food so that they will not get sick. But then the people told each other about this, and they named Sui people as Sui Ren Shi"; "There is also another way to get the fire, which they get two stones and knock at each other to get the fire;" "Sui' means the mirror could get fire in day time while it could also be a stone at night... however,this must be burned in the bowl" In ancient time, "Si Xuan Shi" as the fire officer was the one who served the people to get the fire by using 'Sui' in daytime." Early historical data shows that the people get fire from the nature of the thunderbolt lightning, until they find out that the friction can produce heat to get fire, In Shang Dynasty, "Yang Sui" can be used to condense the light to get fire, while in Iron Age, the people got fire by hitting the stone with sickle... Our ancestors have explored for thousands of years, with unremitting efforts and contributions to fire culture, also accelerated the advance of human civilization, and fire sickle is the history and creation of human beings.

In "Chinese Ancient Famous Ceremony", fire sickle is also called as "Fire Chain", take the fire appliances, made of metal, the shape of sickle back slightly smaller, to percussion flint, flaring spark to get fire. Fire sickle hitting the flint was the early way to get fire, also called as "fire knife", "fire Sui", "soil match". In the Warring States Time, the development of technology civilization prompted the birth of fire sickle, fire sickle began to appear in people's lives, and became the most commonly used, and the most practical fire tools.

\section{CharaCteristic OF STEEL STRUCTURE}

According to historical records, there are many different kinds of shape of flint and model of each era. The normal fire sickle is about $6-8 \mathrm{~cm}$ long, $0.5 \mathrm{~cm}$ wide, and $3-5 \mathrm{~cm}$ high. In the early stage, flint shape is monotonous. Mostly is a long strip shape or $U$ shape, on both sides of the outward hook. Crescent shaped steel is also very common.Because of the need to get fire, flint was often placed on the stove, the woman would hit the flint stone for cooking use; in the middle stage, the style of the flint has begun to change especially the Tibetan nomads.

The prominent is the integral part of steel and iron by cortical purse, there is an upper ring on the purse to wear the rope so that it will be easier to carry. This also meets the characteristics of the nomads; later the fire sickle derived the flint purse (see "Fig. 1"), it is mounted fire sickle, flint, and fire cited box. The ancients often have some waist ornaments, such as their jade, purse, etc., with the flint of the fire sickle box, the purse has gradually become the portable objects of ancient men when they go out, especially when the Manchu people who have been fully grown up and become an adult, they would like to take tobacco as their hobby. So bringing the fire sickle along has become their culture. During Qing Dynasty, the people have regulation for the fire sickle boxes. It also becomes a prerequisites decoration for the robes.

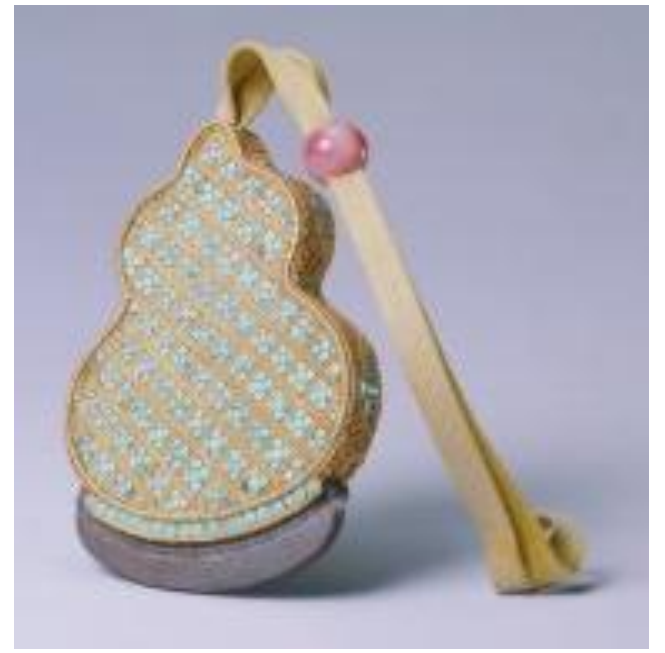

Fig. 1. Jin $\mathrm{Lu}$ wire embedded in the fire falx sets, clear, length $8.7 \mathrm{~cm}$, width $6.5 \mathrm{~cm}$ Source: Taipei National Palace Museum Website 
The cortex beg of the flint is just like a "small purse" which it can hold some idle stuff. To make full use of the space, flint and tinder can be store inside the bag too. To use the flint, first need to open the purse cover, and then take out the flint and tinder. Most people will hold the flint stone with their left hand and put on the flint paper between the fingers. while the right hand will be holding the fire sickle purse. Then use the sickle, to get the fire. This stone tinder process is usually repeated several times until the tinder light up. When there is smoke on tinder, the people can blow directly on the tinder and ignited cigarette. It can also ignite the fire on the fire paper or matchlock. The purse must be waterproof, made by cod skin, wild donkey skin, pig skin and leather etc. animal material production. From the overall shape, the flint is inside the leather bag (see "Fig. 2") on the edge of a crescent shaped fixed iron, iron and flint sickle on the Flint (Flint is also known as a hard stone or stones with irregular edge), rely on spark to lit the tinder (a flammable dried grass pile), people get to use the fire. In the early stage, the material of the flint stone is from Yunnan. It also called "fire grass" plants in the area, the grass love to growth in the mixed forest or small hill, warm and humid climate.

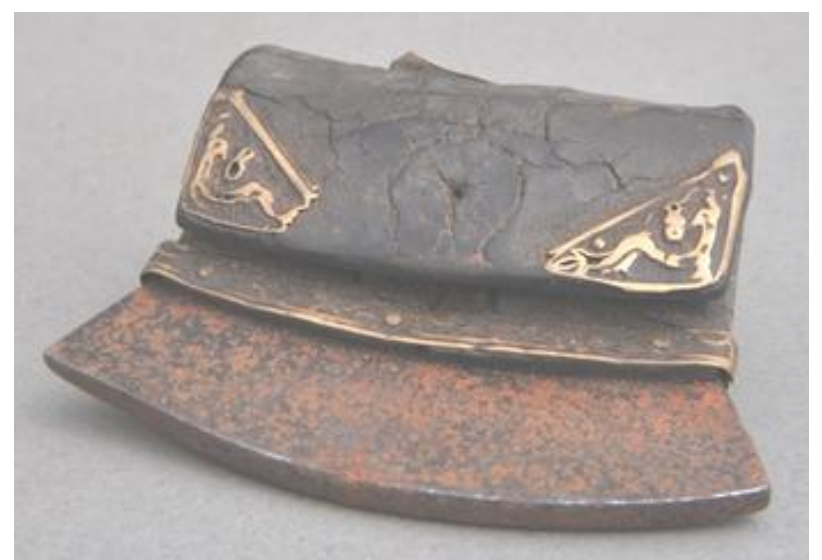

Fig. 2. prime calf leather fire sickle Source: Kangxian Museum official website

\section{The Meaning OF Flint Molding}

There are three kinds of common flint style, first is a shape like a crescent shaped iron, second is overall rectangular iron and third is an oval flint. The flint sickle do not usually open, often passivated, the purpose of doing this is to avoid injury to the fingers and palms, when hand is holding it and do the rapid cross-ignition of the sickle blade and flint to grinding, rubbing, scratching and other actions. If the friction of the fire is not skilled enough, user will easily bruised himself. Passivation of the sickle blade not only to reduce the risk of harm to the palm of your hand, but also to facilitate the preservation of fire sickle. The sickle exposed edge will not accidentally damage the clothing although they are hanging on their waists.

"Fig. 3" shows the Round ring buckle which is on the top of fire sickle, for hanging rings. There are various shape of the ring buckle, round, auspicious clouds shaped, butterfly type copper rings, is suspended in the waist or connected with other parts. Ring buckle on the top of the fire sickle, rounded shape and curved sickle edge has formed a strong visual impact and showing the elegance of the fire sickle structure and the feeling of layering.In addition to the small flint cortex, besides from the similarities and differences between the materials used, it also did patterns modification. The common patterns are round, moire, flower roll pattern, the fire pattern, animal patterns, the sun and "Shou" (life) pattern and other. Corner with two consecutive back to the pattern, decorative ornate fire sickle. Coral or turquoise will also be embedded in the center pattern, surrounded by a row of sterling silver beads and other shapes. The use of exaggeration, extraction, abstraction and other techniques for artistic decoration, workmanship extremely delicate, wonderful and coincidence." For quite some time, people are using natural elements such as the sun, clouds, fire, dragon and bat to make fire ornament elements on the use of fire sickle. Different pattern decoration represents their own unique meaning. For example, "Peace and good fortune", "happiness and well-being", "blessing" and "life". Auspicious words pattern reflects the people placed on the fire sickle of happiness, longevity, wisdom, strength, luck, wish things come true, people believe in harmony with nature, treasure, protect the concept of nature, into people's lives .

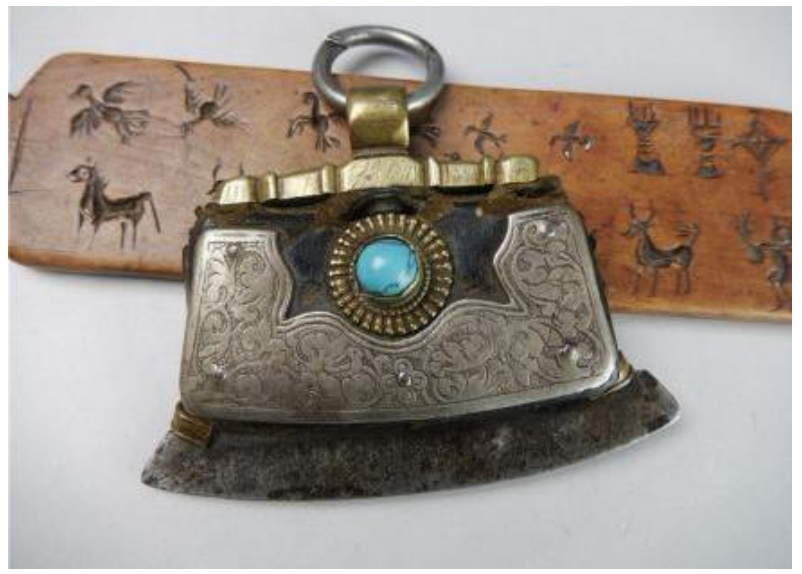

Fig. 3. Round ring buckle. Source: ancient spring garden network

\section{THE EVOLUTION OF FLINT FUNCTION}

The use of fire sickle and people's lives are closely related, it has gradually become an indispensable part of people's lives. So the use of fire sickle features are changing slowly, it began not only has a practical function, but also highlight the identity by hanging waist accessories. Tibetan region has an embedded coral fire sickle, bladder decorated exquisite, gorgeous, inlaid silver, copper carving, but also to coral, loose green stone embellishment. Also used to decorate embellishment clothing, or as a tool for possession of the accessories, and entrusted with a line hanging in the waist line. Especially when the Tibetans need to hunt and light up the fire, it is easy to carry. Therefore, the fire sickle is undoubtedly the best tool for Tibetan nomads. Of course, as people needs fire, they will go out to get the fire. However, fire sickle holders will highlight personal identity, worth and desire. As a result, "fire sickle production process more particular about the style with their own characteristics, from 
a single practical gradually evolved into a portable convenience, with a decorative process and reflect the level of one self-status."

There is a huge difference between regions and classes due to geographical, environmental distribution. Ordinary civilians use the normal fire sickle generally made with pigskin or donkey skin, the process of this fire flint is rougher, partial is emphasis on the function and not the decorative features.Part of the secluded desolate areas of the fire sickle most of them are just a single piece of iron, smoking people will smoke and hang a small tin on their old smoke bag, so that they can light up their cigarette any time. They will not too particular on the shape of the fire sickle (see "Fig. 4"). Some of the European torch made of monolithic iron plate and other shapes, in addition to the blade part of the other parts can be used as a handle when the ignition. Tibetan fire sickle with Tibet rough style, not only big, the shape of bold, aristocratic use of fire sickle is beautiful too, they decorated with gold, silver, copper decoration, inlaid with red coral, turquoise and a variety of precious stones, jewels, elegant.

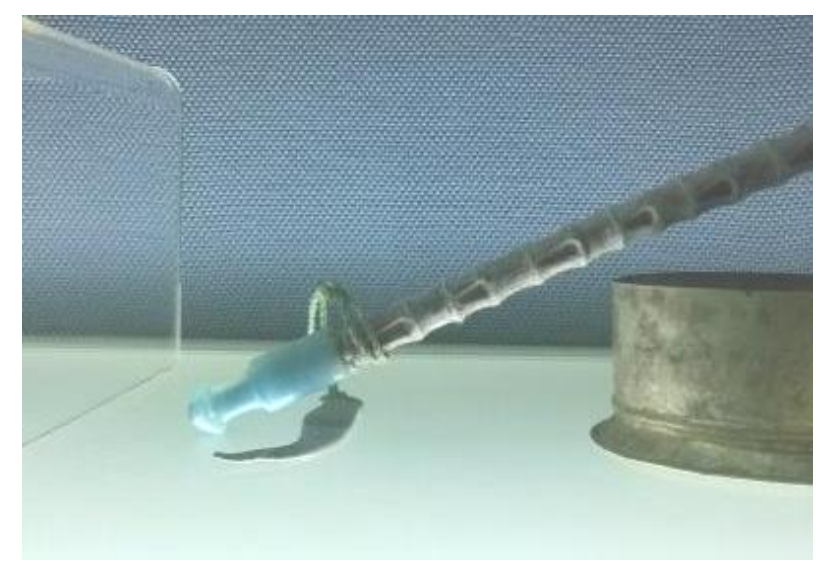

Fig. 4. fire sickle iron. Source: Author photo at the Shanghai Tobacco Museum

Even the royal family use large size of the Tibetan fire sickle, noble and generous. Mongolian fire sickle shape is usually oval, but also rectangular and sickle-shaped, more peculiar shape, and some firecrackers will be engraved on the purse dragon cloud patterns, lifelike. Some even put their purse with gold and silver, pearls and agate, will be coupled with exquisite little lock.In order to meet the different levels of the use of the crowd, craftsmen in the production of fire sickle will often made the fire sickle according to the user's habits, in order to highlight the status of the person.

Crescent shape lines are smooth, the appearance of exquisite smart fire sickle is the favorite thing of the owner, simple, elegant and not personality. As the fire sickle are handmade, few re-sample, some of which very rich artistic attainments, and even precious materials as decorative embellishment. Now it has become an antiques of Tibetan city, it has a unique era of living things and also unique history of "Chen Yun." In the Qing Dynasty, fire sickle or betrothal are one of the dowry, to marry married a virtuous wife, to serve the father and mother in law. The 28th
Chapters of Qing Dynasty Novel "Heroines of Children": "One stone and fire sickle, holding a lamp on its hand, with a grinding stone..." The customs marriage of many ethnic minorities, fire sickle also plays an important role, due to the use of a wide range of fire sickle, and durable, handed down the product is also relatively more. In the early stage, there are many definition about fire sickle definition, such as lighters, accessories, waist hanging, life appliances, antique objects have been playing an unknown role, and now the fire sickle is often classified as miscellaneous small pieces, indicating that it is still in a lower grades level. With the widespread use of matches, fire sickle has gradually withdrawn from the stage of history, there are current just a few fire surviving, many young people have not even seen fire sickle. Fire sickle has become a rare collection.

Fire sickle also derived some of the language and the invention of Chinese characters and changes. Some small area dialects are still retain the use of words "fire sickle", such as Vietnamese (Yi). These cultures reflect the fire sickle from the other side. And this is closely related to people cultural life with significant impact.

\section{CONCLUSION}

From drilling the wood for fire in the ancient times to the transformation of the Iron Age flint, this has greatly facilitate the human to get and use fire, not only convenient for people's life, but also development a fire civilization. A small flint, the confusion between the meaning and practical, carving and art in one have fully demonstrated the fascination of China traditional culture. Flint once existed in the hands of our ancestors, has bring convenient to our life. And replacement with kindling acquisition is more applicable and convenient. Although flint has fade out of our sight in daily life, but in the hands of foreign rock climbing off-road enthusiasts, fire sickle has always been a tool for everyone to get fire. Fire sickle has always been a tool that we love to get the fire. Knife and fire sickle is a must for mountaineering bag. There is a reason, although outdoor lighter is convenient but there are too many factors of instability, especially in harsh environments of the place. Fire sickle can last longer than the lighter because it is more resistant to moisture.

Although flint has become the memory of the past, and become a history, however, people getting fire by using the flint has been lasting for thousands of years. Therefore, the value of the fire sickle is not only apparatus and tools for human to survive, but later evolved into tool accessories, waist hanging and also reveal and highlight the identity symbol of a person. The function of fire sickle is diverse, which reflects the artistic research value of fire sickle, and has important enlightening significance for the design of later-related fire extinguishers.

\section{REFERENCES}

[1] Waffle editor. China naming ceremony of ancient (lower), Ji'nan press, October 1993, page $100^{\text {th }}$. 
[2] Li Yongjin. rare Tibetan words match, Shanghai Bookstore Publishing House, 2010.1.

[3] Wang Hu editor.Chinese traditional instrument design research. Vol. three, Nanjing: Jiangsu Fine Arts Publishing House, 2010.1.

[4] Zhao Jing. a Inner Mongolia Agricultural University study, it was decorated in traditional Mongolian, 2014.6.

[5] Wen Kang.the children's Heroes. Zhongzhou ancient books publishing house, 2010.1 .

[6] Tianzibing. Chinese art history, Oriental publishing, 2010.4.

[7] Hua Jueming editor.in chief of the Chinese arts and crafts, special technology, Zhengzhou,, 2014.6.

[8] Yan Feng. edited by Chen Fengwei, a concise dictionary antique, Cambridge University Press, 1992.6.

[9] Huang Linton editor. Li Lixin et al., China-art equipment volume, Nanjing University press, 2011.5.

[10] Edited by Qi Linlin. ancient accessories, Mount Huangshan publishing house, 2012.8 . 